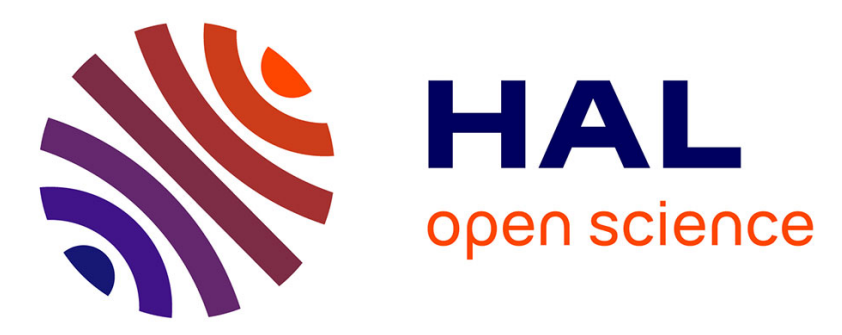

\title{
Integrated optimal design of a hybrid locomotive with multiobjective genetic algorithms
}

\author{
Cossi Rockys Akli, Bruno Sareni, Xavier Roboam, Alain Jeunesse
}

\section{To cite this version:}

Cossi Rockys Akli, Bruno Sareni, Xavier Roboam, Alain Jeunesse. Integrated optimal design of a hybrid locomotive with multiobjective genetic algorithms. International Journal of Applied Electromagnetics and Mechanics, 2009, vol. 30, pp.151-162. 10.3233/JAE-2009-1018 . hal-00763618

\section{HAL Id: hal-00763618 \\ https://hal.science/hal-00763618}

Submitted on 11 Dec 2012

HAL is a multi-disciplinary open access archive for the deposit and dissemination of scientific research documents, whether they are published or not. The documents may come from teaching and research institutions in France or abroad, or from public or private research centers.
L'archive ouverte pluridisciplinaire HAL, est destinée au dépôt et à la diffusion de documents scientifiques de niveau recherche, publiés ou non, émanant des établissements d'enseignement et de recherche français ou étrangers, des laboratoires publics ou privés. 


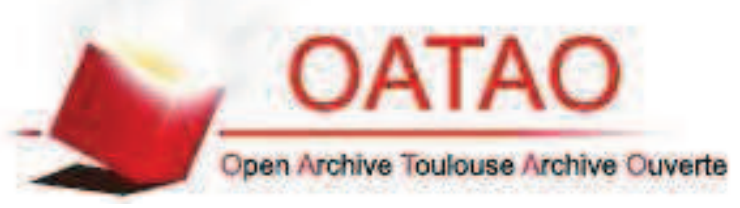

\section{Open Archive TOULOUSE Archive Ouverte (OATAO)}

OATAO is an open access repository that collects the work of Toulouse researchers and makes it freely available over the web where possible.

This is an author-deposited version published in : http://oatao.univ-toulouse.fr/ Eprints ID : 7978

To link to this article : DOI: $10.3233 / \mathrm{JAE}-2009-1018$

URL : http://dx.doi.org/10.3233/JAE-2009-1018

To cite this version :

Akli, Cossi Rockys and Sareni, Bruno and Roboam, Xavier and Jeunesse, Alain Integrated optimal design of a hybrid locomotive with multiobjective genetic algorithms. (2009) International Journal of Applied Electromagnetics and Mechanics, vol. $30\left(\mathrm{n}^{\circ} 3-\right.$ 4). pp. 151-162. ISSN 1383-5416

Any correspondence concerning this service should be sent to the repository administrator: staff-oatao@listes.diff.inp-toulouse.fr 


\title{
Integrated optimal design of a hybrid locomotive with multiobjective genetic algorithms
}

\author{
C.R. Aklia, , B. Sareni ${ }^{\mathrm{a}, *}$, X. Roboam ${ }^{\mathrm{a}}$ and A. Jeunesse ${ }^{\mathrm{b}, *}$ \\ ${ }^{a}$ Université de Toulouse, LAPLACE, UMR CNRS-INPT-UPS (site ENSEEIHT), Toulouse Cedex 7 , \\ France \\ ${ }^{\mathrm{b}} \mathrm{SNCF}$, Centre d'Ingénierie du Matériel, Le Mans, France
}

\begin{abstract}
In this paper, the Integrated Optimal Design (IOD) approach for energetic system design is discussed. IOD aims at concurrently optimizing the architecture, the element sizing and the energy management in an energetic system. IOD leads to complex optimization problems (typically mixed variable problems with several constraints and multiple objectives) which can be solved with direct optimization methods. We illustrate the interest of this approach through the design of a hybrid environmentally friendly locomotive moved by four DC motors supplied by a diesel engine generator in association with electric storage elements (batteries and ultracapacitors).
\end{abstract}

Keywords: Integrated optimal design, multidisciplinary design optimization, hybrid locomotive, ecodesign

\section{Introduction}

The design of electrical energetic systems represents a societal challenge. The increasing demands in terms of energetic needs and efficiency requirements for energetic systems have to be fulfilled. Instead of current devices which are generally oversized in relation to their power needs, innovative systems should now be designed as accurately as possible to avoid energetic wastes. The difficulties related to the optimization of such systems are related to several features:

- these systems are characterized by a high level of complexity, being composed of multiple subsystems whose architecture and dimensioning have to be determined to reach optimal performance

- these systems are strongly heterogeneous, multi-domain, being composed of elements with different physical types (electric, mechanic, thermal) and multi-time scaled models. This leads the designer to raise the question of the level of representation for the system elements and the corresponding model types (analytical, numerical such as algebra-differential equations or finite element models) in relation to a compromise associated with accuracy and computational costs. Because of these main difficulties, the design process was usually simplified by using a sequential approach divided in three different steps:

\footnotetext{
* Corresponding authors: B. Sareni, Université de Toulouse, LAPLACE, UMR CNRS-INPT-UPS (site ENSEEIHT), 2 rue Camichel, 31071 Toulouse Cedex 7, France. E-mail: sareni@laplace.univ-tlse.fr. A. Jeunesse, SNCF, Centre d’Ingénierie du Matériel, 4 Allée des gémeaux - 72100 Le Mans, France. E-mail: alain.jeunesse@ sncf.fr.
} 
- step 1: find the most suitable system architecture

- step 2: optimize the element sizing

- step 3: find an optimal energy management strategy for the system

Note that step 2 and step 3 are sometimes reversed for hybrid systems. However, couplings existing between these factors and their influence on the global system efficiency require the evolution toward a global optimization approach. Various methodologies have been recently developed for design optimization including Multidisciplinary Design Optimization in aeronautics [1,2], Integrated Design in Electronics and Power Systems [3-5] or Simultaneous Design in Automatic and Control Systems [6,7].

In this work a typical example of IOD problem in electrical engineering is presented, illustrating the design of a hybrid locomotive devoted to non-electrified areas. The French national railways company (SNCF) and research academic institutes are involved in a project called PLATHEE ${ }^{1}$ [8] which aims at investigating and testing energy efficient and environmentally friendly traction systems. In this context, a platform called LHyDIE (Hybrid Locomotive for Demonstration and Investigations in Energetics) is developed. Even if the platform specifications have already been determined from earlier studies $[9,10]$ with a traditional sequential approach of the design, this work compares the obtained results with those resulting from a global IOD methodology.

\section{The locomotive architecture and the energy management strategy}

LHyDIE is built from a conventional shunting and switcher diesel locomotive named "BB63000" moved by four electric motors fed by a diesel generator of $600 \mathrm{~kW}$. One goal of the PLATHEE project is to reduce the diesel engine size by hybridizing this energetic source with batteries and ultracapacitors (see Fig. 1). All sources are coupled to a DC bus through static converters. Batteries (or ultracapacitors) are composed of $N P_{B T}$ blocks (respectively $N P_{S C}$ blocks) connected in parallel to the DC bus, each block containing $N S_{B T}$ battery cells (respectively $N S_{B T}$ ultracapacitor cells) in series. The energy management in the locomotive is based on a frequential approach which dispatches the power $\left(P_{M}\right)$ required by the driving mission according to the dynamic of the embedded energetic sources (see Fig. 2). The high frequency part of the power demand is devoted to the ultracapacitors $\left(P_{S C}\right)$ while the lower frequency part is shared between the batteries $\left(P_{B T}\right)$ and the diesel engine generator $\left(P_{D E}\right)$. The frequency distribution of the locomotive mission uses two control parameters: the cutoff frequency $\left(F_{c}\right)$ of a lowpass filter and the diesel generator power $P_{D E}$.

The locomotive is devoted to shunting services and should fulfill the mission profile of Fig. 3. It has been shown in [9] that this profile dominates in terms of power and energy other usual missions. Therefore, the mission of Fig. 3 is considered as the most difficult mission and is taken as reference in the design process.

\section{The energetic models}

All models dedicated to the locomotive IOD have been developed in Matlab/Simulink. They concern the energetic behavior, the embedded energetic source volumes, the global system cost and the battery lifetime

\footnotetext{
${ }^{1}$ PLATHEE is a French acronym which means "Energy Efficient and Environmentally Friendly Train Platform".
} 


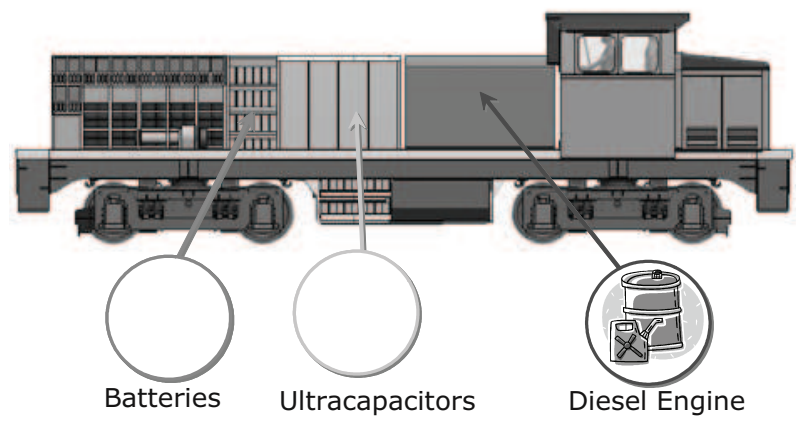

Fig. 1. The LHyDIE locomotive architecture.

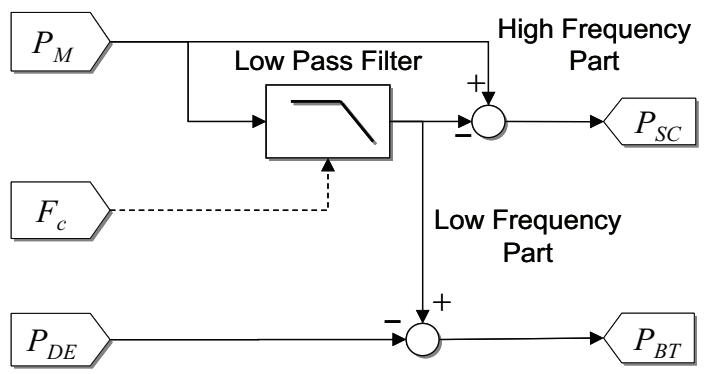

Fig. 2. The main principle of the energy management strategy.

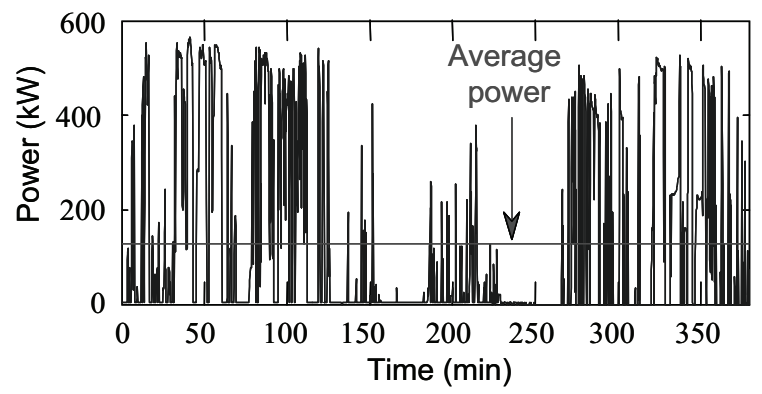

Fig. 3. A typical difficult locomotive mission profile.

\subsection{The power flux model}

The power flux model determines the characteristics of the power sources of the locomotive i.e. the power $(P)$, the energy $(E)$ and the state of charge $(S O C)$ for the storage elements. Considering a given power mission $P_{M}$, an energy management controller provides the power reference values for the diesel engine $\left(P_{D E r e f}\right)$, the ultracapacitors $\left(P_{S C r e f}\right)$ and the batteries $\left(P_{B T r e f}\right)$. These references are obtained according to the principle of Fig. 2 and by taking power losses in the storage elements and the associated state of charge limits. The power flux model of the diesel engine is given in Fig. 4. It allows us to obtain from the diesel engine power reference $\left(P_{D E r e f}\right)$ and a start/stop command $\left(S S_{D E}\right)$ the diesel engine power $\left(P_{D E}\right)$, the corresponding energy $\left(E_{D E}\right)$, the quantity of fuel consumed $\left(Q_{f u e l}\right)$ and the corresponding quantity of emitted carbon dioxide $\left(Q_{\mathrm{CO}}\right)$. The parameters of this model are the converter 
Table 1

The parameters of the battery and ultracapacitor power flux models

\begin{tabular}{lll}
\hline & Ultracapacitors & Batteries \\
\hline Efficiency (including the converter efficiency) & $\eta_{S C}=91 \%$ & $\eta_{B T}=80 \%$ \\
Discharge limit & $P_{d c h \max }=475 \mathrm{~kW}$ & $P_{d c h \max }=380 \mathrm{~kW}$ \\
Charge limit & $P_{\text {chmax }}=-475 \mathrm{~kW}$ & $P_{\text {chmax }}=-192 \mathrm{~kW}$ \\
\hline
\end{tabular}

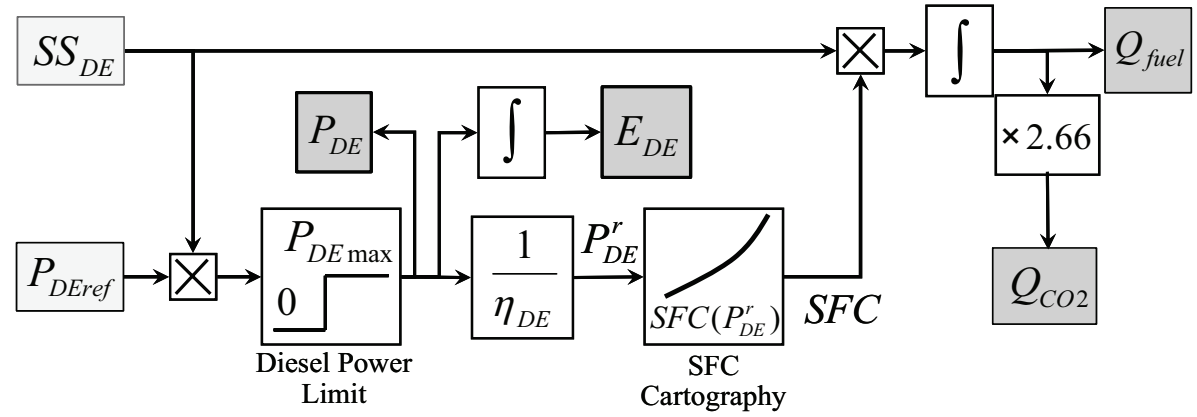

Fig. 4. The power flux model of the diesel engine.

efficiency associated with the diesel engine (typically $\left.\eta_{D E}=96 \%\right)$, the diesel power limit $\left(P_{D E \max }\right)$ and the Specific Fuel Consumption $(S F C)$ characteristic. This characteristic has been extrapolated with a five order polynomial as a function of the diesel engine power as follows [9],

$$
S F C\left(P_{D E}\right)=S F C_{N} \sum_{i=0}^{5} b_{i}\left(\frac{P_{D E}}{P_{D E N}}\right)^{i}
$$

where the polynomial coefficients are $b_{0}=1.94, b_{1}=-6.44, b_{2}=18.57, b_{3}=-27.22, b_{4}=19.72$, $b_{5}=1$.94. $P_{D E N}$ denotes the nominal power of the diesel engine and $S F C_{N}$ represents the specific fuel consumption at this power estimated at $202.45 \mathrm{~g} / \mathrm{kW}$. The previous relation has been validated for three diesel engines of the Fiat Powertrain Technologies Group. Note that the specific fuel consumption is optimal when the diesel engine operates at its nominal power $P_{D E N}$. Therefore, the energy management controller tends to maintain the diesel engine power reference close to this power.

The quantity of $\mathrm{CO}_{2}$ emitted (in $\mathrm{kg} / \mathrm{L}$ ) is directly proportional to the fuel quantity consumed and is estimated as follows [11]:

$$
Q_{\mathrm{CO} 2}=2.66 \times Q_{\text {fuel }}
$$

The power flux model of the storage element packs is given in Fig. 5. The model is identical for batteries and ultracapacitors so the $s$ index in Fig. 4 can be replaced by $B T$ for the battery pack and $S C$ for the ultracapacitor pack. The parameters of this model and their values are given in Table 1 .

\subsection{The electric model}

The electric model specifies voltages and currents from the power flux model. A $R C$ electric model is used to obtain the electrical variables in an utltracapacitor or battery cell (see Figs 6 and 7). Technological data values corresponding to EPCOS 5000 F/2.5V ultracapacitor cells and Hoppecke FNC 1502HR 


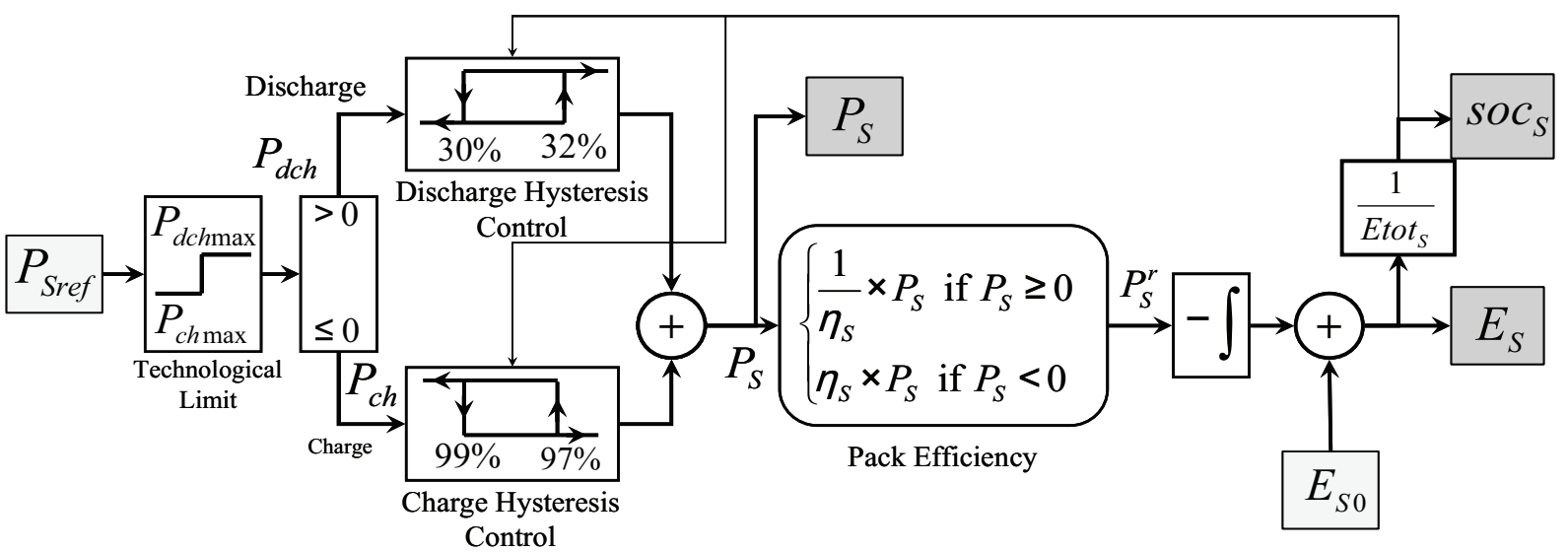

Fig. 5. The power flux model of a storage element pack (ultracapacitors or batteries).

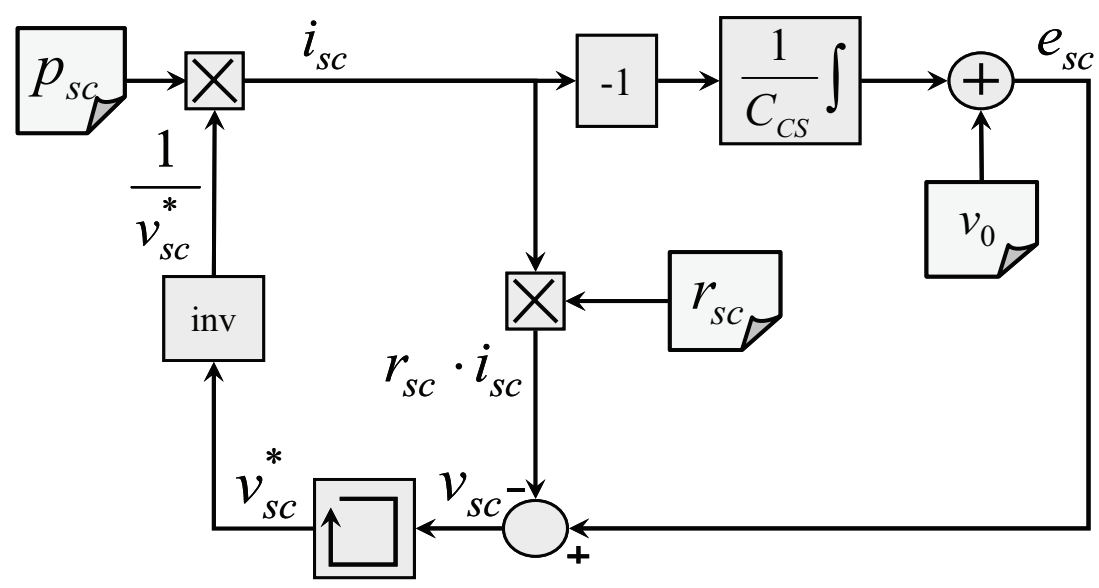

Fig. 6. The electric model of an ultracapacitor cell.

battery cells of $135 \mathrm{Ah}$ are considered in these models. In particular the battery resistance $r_{B T}$ and its emf $e_{B T}$ are interpolated from the manufacturer data as a function of the cell state of charge $q$ :

$$
\left\{\begin{array}{r}
r_{B T}=2.83-12.88 q+24.88 q^{2}-20.83 q^{3}+6.28 q^{4} \\
e_{B T}=0.99+1.06 q-1.82 q^{2}+1.11 q^{3}
\end{array}\right.
$$

The ultracapacitor resistance is supposed to take a constant value of $350 \mathrm{~m} \Omega$. Current and voltage in a cell are computed from the cell power $\left(p_{S C}\right.$ or $\left.p_{B T}\right)$ as follows:

$$
\left\{\begin{array}{c}
p_{S C}=P_{S C} /\left(N P_{S C} \times N S_{S C}\right) \\
p_{B T}=P_{B T} /\left(N P_{B T} \times N S_{B T}\right)
\end{array}\right.
$$

where $N S_{B T}$ and $N P_{B T}$ denote the number of battery cells in series and the associated number of branches in parallel. $N S_{S C}$ and $N P_{S C}$ represent the same variables for ultracapacitors. 


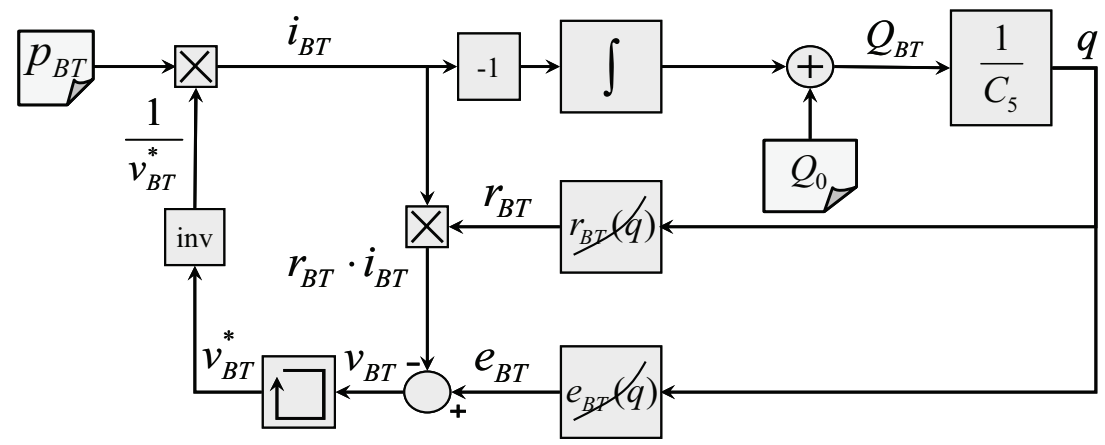

Fig. 7. The electric model of a battery cell.

\subsection{The sizing model}

The global volume available for the embedded energetic sources and their associated devices (static converters, thermal radiators, filter elements) is about $32 \mathrm{~m}^{3}$. Therefore, the volume of each component has been estimated with empiric relations from manufacturer data, in order to fulfill space constraints. The diesel engine volume $\Omega_{D E}$ in $\mathrm{m}^{3}$ has been interpolated with a linear function as follows:

$$
\Omega_{D E}=3 \times 10^{-5} P_{D E N}+0.03
$$

The ultracapacitor and battery volumes $\left(\Omega_{B T}\right.$ and $\left.\Omega_{S C}\right)$ are calculated from the corresponding unit cell volumes $\left(\Omega_{B T 0}\right.$ and $\left.\Omega_{S C 0}\right)$, the total number of cells and by means of assembly coefficients $\left(\lambda_{B T}\right.$ and $\left.\lambda_{S C}\right)$ :

$$
\left\{\begin{array}{l}
\Omega_{B T}=\lambda_{B T} \times N P_{B T} \times N S_{B T} \times \Omega_{B T 0} \\
\Omega_{S C}=\lambda_{S C} \times N P_{S C} \times N S_{S C} \times \Omega_{S C 0}
\end{array}\right.
$$

where $\Omega_{B T 0}=4.33 \times 10^{-3} \mathrm{~m}^{3}$ and $\Omega_{S C 0}=9.9 \times 10^{-4} \mathrm{~m}^{3}$. The assembly coefficients, which take into account of the interspaces between each cell and the corresponding cooling devices are estimated to $\lambda_{B T}=1.8$ and $\lambda_{S C}=2.3$. The volume of the static converters associated with ultracapacitor and battery blocks $\left(\Omega_{C S C}\right.$ or $\left.\Omega_{C B T}\right)$ is approximated with the corresponding filtering inductance volume $\Omega_{S}$ (i.e. $\Omega_{L S C}$ or $\Omega_{L B T}$ ). Each static converter is composed of $n_{l}$ parallel chopper legs with a filtering inductance $L_{S}$ (i.e. $L_{B T}$ or $L_{S C}$ ) defined as

$$
L_{S}=\frac{V_{\text {bus }}}{4 F_{S W} \Delta i_{S}}
$$

where $F_{S W}$ denotes the converter switching frequency, $V_{\text {bus }}$ represents the bus voltage and $\Delta i_{S}$ is the current ripple (typically limited to $60 \mathrm{~A}$ ) in the inductance. The number of chopper legs is chosen as the minimum integer value which maintains the IGBT current below $450 \mathrm{~A}$, i.e.

$$
\frac{i_{S \max }}{n_{l}}+\frac{i_{S}}{2} \leq 450
$$

where $i_{S \max }$ denotes the maximum current in the storage cell (i.e. $i_{B T \max }$ or $i_{S C \max }$ ). The maximum energy in the filtering inductance is obtained as follows:

$$
W_{\max }=\frac{1}{2} L_{S}\left(\frac{i_{S \max }}{n_{l}}+\frac{i_{S}}{2}\right)^{2}
$$


The corresponding inductance volume $\Omega_{L S}$ is calculated from the maximum energy using a second order polynomial which interpolates manufacturer data

$$
\Omega_{L S}=a_{0}+a_{1} W_{\max }+a_{2} W_{\max }^{2}
$$

where $a_{0}=1.3392, a_{1}=0.1549, a_{2}=0.0014$. Finally, the global converter volumes associated with the ultracapacitor and battery packs are deduced from the corresponding filtering inductance volumes, the number of parallel blocs in each pack, the number of chopper legs and a correction coefficient $\lambda_{C}$ (typically $\lambda_{C}=1.2$ ) taking into account of electronics parts (IGBTs and associated cooling devices).

$$
\Omega_{C S}=\lambda_{C} n_{l} N P_{S} \Omega_{L S}
$$

\subsection{The battery and ultracapacitor lifetime models}

The battery lifetime model is related to the number of cycles to failure $\left(c_{F}\right)$ which can be expressed as a function of the depth of discharge ( $D O D$, specified in \%) [12]. A qualitative approximation of the $c_{F}$ coefficient has been derived in [9] for the Hoppecke FNC 1502HR battery cells for nominal conditions (temperature between $30^{\circ} \mathrm{C}-40^{\circ} \mathrm{C}$, charge at $C_{5}$ and discharge at $2 C_{5}$ ):

$$
c_{F}(D O D)=966 \times D O D^{-2.37}
$$

Considering the number of cycles to failure for $D O D=100 \%$ as a reference, we can express a "cycle weight" $w_{C Y C L E}$ for lower $D O D$ s as:

$$
w_{C Y C L E}(D O D)=\frac{c_{F}(100 \%)}{c_{F}(D O D)}
$$

This weight evaluates the effect of a cycle for a given $D O D$ in relation to a cycle for full $D O D$. Since battery $S O C$ characteristics during a particular driving mission generally consist in various cycles with different $D O D$, a global battery stress estimator $L F T_{B T}$ evaluates the battery lifetime from the total number of cycles $N_{C Y C L E}$ at a given $D O D$. To compute this estimator, the $D O D$ range is divided into 10 uniformly spaced intervals. Then, the number of cycles $N_{C Y L E}(i)$ which occurs in a $D O D$ interval $i$ is determined from the battery SOC associated with the locomotive mission. Finally, the $L F T_{B T}$ estimator is calculated by globalizing all cycles in all intervals, taking account their weight according to the corresponding $D O D$ :

$$
L F T_{B T}=N P_{B T} \times N S_{B T} \times \sum_{i=1}^{10} w_{C Y C L E}(i) \times N_{C Y C L E}(i)
$$

where $w_{C Y C L E}(i)$ denotes the cycle weight at the middle of the $D O D$ interval $i$ considered. The same approach is used for calculating the ultracapacitors lifetime considering linear distributed weights and a cycle to failure reference of 500000 at $100 \%$ of $D O D$.

\subsection{The cost model}

The global cost in $€$ of the diesel engine $C_{D E}$, including its installation, can be interpolated by a linear function versus the nominal power:

$$
C_{D E}[€]=0.28 P_{D E N}+14500
$$


To take into account repairs and maintenances, the previous relation has been modified. It has been estimated by the SNCF that the cost of the diesel engine over 10 years is 3 times higher than the purchase cost. Therefore, the previous relation becomes:

$$
C_{D E}[€ / \text { year }]=\frac{3}{10}\left(0.28 P_{D E N}+14500\right)=0.084 P_{D E N}+4350
$$

The cost of the battery cells is calculated from the cycle cost which allows taking account of purchase costs (including installation costs) as well as maintenance costs (directly related to the battery lifetime). A battery cycle cost has been estimated to $0.122 €$. By considering the $L F T_{B T}$ stress estimator, the battery cost per year $C_{B T}$ can be expressed as:

$$
C_{B T}[€ / \text { year }]=0.122 \times L F T_{B T} \times \frac{\Delta \tau_{\text {year }}}{\Delta \tau}
$$

where $\Delta \tau_{\text {year }}$ represents the locomotive exploitation in one year (typically 8 hours per days, i.e. 2880 hours per year) and where $\Delta \tau$ denotes the total mission duration. Note that the ultracapacitor and battery cells are fully charged at the beginning of a mission. If their state of charge at the end of the mission differs from their initial state, it is advisable to maintain the diesel engine in order to fully recharge the storage elements. Therefore, an additional charging period $\Delta \tau_{\text {charge }}$ is added to the standard mission duration $\Delta \tau_{M}$ to calculate the global mission duration $\Delta \tau$. The ultracapacitor cost per year $C_{B T}$ is similarly computed by considering a cycle cost of $3 \times 10^{-4} €$.

Finally, as the gasoline cost is about $1.35 €$ per liter, the global cost per year is estimated as

$$
C_{\text {fuel }}[€ / \text { year }]=1.35 Q_{\text {fuel }} \frac{\Delta \tau_{\text {year }}}{\Delta \tau}
$$

\section{The initial configuration of the locomotive}

Because of time constraints in the PLATHEE project, the LHyDIE platform was first designed using a traditional approach which sequentially optimizes the system architecture, the energy management strategy and the element sizing [10]. Multiple trade-offs associating energy efficiency, volume, cost and battery stress were considered but no optimization was actually performed at a global system level. The initial configuration consists in a diesel engine generator of $215 \mathrm{~kW}$ nominal power connected to a 540 V DC bus, in association with 8 blocks of 200 ultracapacitor cells in series and 4 blocks of 300 battery cells in series.

\section{The integrated optimal design of the hybrid locomotive}

Instead of finding the locomotive characteristics through a sequential process and by a priori setting some design variables, we investigate an integrated design approach based on a global optimization.

\subsection{The design variables}

The design variables and their associated bound are shown in Table 2. Four of them are discrete and three are continuous. 
Table 2

The hybrid locomotive design variables

\begin{tabular}{lcl}
\hline Design variable & Nature & Bounds \\
\hline Number of battery cells in series & Discrete & $0 \leq N S_{B T} \leq 542$ \\
Number of battery blocks in parallel & Discrete & $0 \leq N P_{B T} \leq 32$ \\
Number of ultracapacitor cells in series & Discrete & $0 \leq N S_{S C} \leq 262$ \\
Number of ultracapacitor blocks in parallel & Discrete & $0 \leq N P_{S C} \leq 60$ \\
Nominal diesel engine power $[\mathrm{kW}]$ & Continuous & $50 \leq P_{D E N} \leq 600$ \\
DC bus voltage [V] & Continuous & $50 \leq V_{\text {bus }} \leq 650$ \\
Converter switching frequency $[\mathrm{kHz}]$ & Continuous & $1 \leq F_{S W} \leq 10$ \\
\hline
\end{tabular}

\subsection{The design constraints}

Six inequality constraints classically formulated in terms of minimization (i.e. $g_{i} \leq 0$ ) have to be fulfilled to ensure the locomotive design feasibility. These constraints can be separated into two groups. The first three constraints do not require the simulation of the locomotive behavior to be computed. They are qualified as pre-simulating constraints. On the other hand, the other three constraints are evaluated from the locomotive simulation on its driving mission. They are qualified as post-simulating constraints. The computational time devoted to the simulation of the driving mission is about $35 \mathrm{~s}$ on a standard PC computer. To improve the CPU time of the optimization process, the simulation of the locomotive on its driving mission is not performed if a pre-simulating constraint is not fulfilled. In this case, post-simulating constraints receive the maximum penalty $\left(g_{i} \rightarrow+\infty\right)$.

\subsubsection{Pre-simulating constraints}

The first constraint $g_{1}$ verifies that the global volume of the embedded energetic sources is lower than $32 \mathrm{~m}^{3}$

$$
g_{1}=\Omega_{S C}+\Omega_{B T}+\Omega_{D E}-32 \leq 0
$$

By considering the boost structure of the DC-DC converters related to the storage elements, the maximum values for the battery and ultracapacitor packs are limited by the maximum duty cycle $\alpha_{\max }$ (typically $\alpha_{\max }=93 \%$ ) which implies two additional constraints

$$
\begin{aligned}
& g_{2}=N S_{B T} v_{B T \max }-\alpha_{\max } V_{\text {bus }} \leq 0 \\
& g_{3}=N S_{S C} v_{S C \max }-\alpha_{\max } V_{\text {bus }} \leq 0
\end{aligned}
$$

where $v_{S C \max }$ and $v_{B T t \max }$ represent the maximum voltage values for ultracapacitor and battery cells $\left(v_{S C \max }=2.5 \mathrm{~V}\right.$ and $\left.v_{B T \max }=1.34 \mathrm{~V}\right)$.

\subsubsection{Post simulating-constraints}

From the locomotive simulation on its mission, we can obtain the maximum current in all utracapacitor and battery cells. Then, it is possible to better approximate the system volume with the computation of static converter volumes. The previous volume constraint can be updated as follows

$$
g_{4}=\Omega_{S C}+\Omega_{B T}+\Omega_{D E}+\Omega_{C B T}+\Omega_{C S C}-32 \leq 0
$$

The charging period $\Delta \tau_{\text {charge }}$ required at the end of the driving mission to fully charge the storage elements is limited in relation to the standard mission duration $\Delta \tau_{M}$ with the $g_{5}$ constraint defined as:

$$
g_{5}=\frac{\Delta \tau_{\text {charge }}}{\Delta \tau_{M}}-0.4 \leq 0
$$




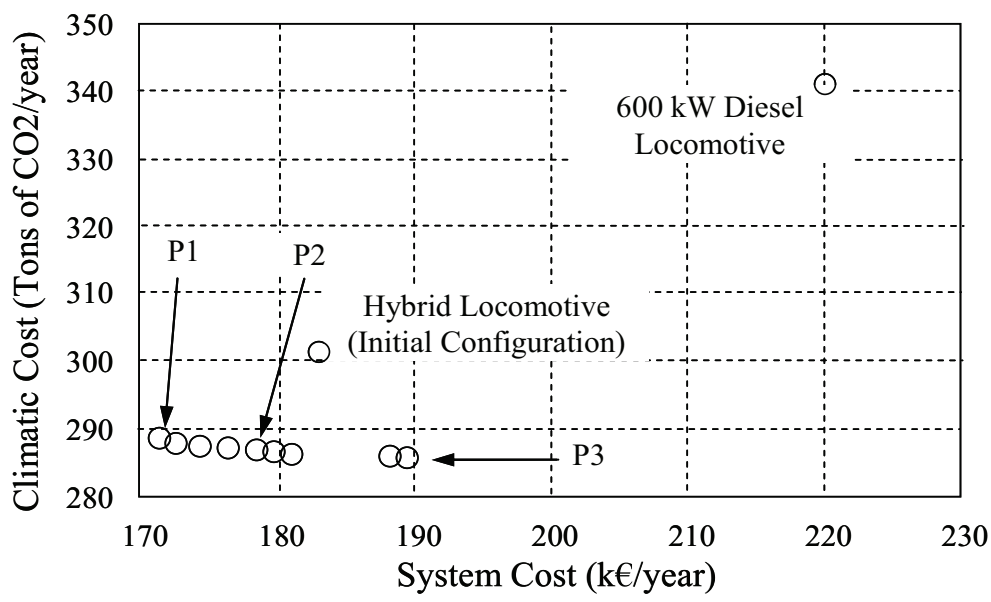

Fig. 8. The Pareto-optimal configurations of the hybrid locomotive.

Finally, the last constraint is related to the mission fulfillment. Solutions are supposed to be feasible if they are capable of complying with the mission defined in Fig. 3 or if the energetic deficit $E_{d}$ on the mission in relation to the global energy required $E_{m}$, is lower than $1 \%$. This leads to the following constraint

$$
g_{6}=\frac{E_{d}}{E_{m}}-0.01 \leq 0
$$

\subsection{The locomotive optimization}

The main goal of the PLATHEE project resides in the reduction of the carbon dioxide quantity emitted by diesel locomotives. Therefore, the first objective $f_{1}$ to be minimized is a climatic cost per year, defined as

$$
f_{1}=Q_{C O 2} \frac{\Delta \tau_{\text {year }}}{\Delta \tau}
$$

where $\Delta \tau_{\text {year }}$ and $\Delta \tau$ are defined as previously. The second objective $f_{2}$ is related to the global system cost of the energetic sources (including purchase costs, component lifetime and fuel consumption)

$$
f_{2}=C_{D E}+C_{B T}+C_{S C}+C_{\text {fuel }}
$$

The non-dominated sorting genetic algorithm (NSGA-II) [13] is used to solve this multiobjective problem. The crossover and mutation probabilities are $p_{c}=1$ and $p_{m}=0.1$. The population and archive sizes are set to 100 and the generation number is $G=500$. Five independent runs are made to take into account of the NSGA-II stochastic feature. The Pareto-optimal configurations of the hybrid locomotive obtained from these runs are shown in Fig. 8. In this figure, the LHYDIE initial configuration and a $600 \mathrm{~kW}$ diesel locomotive (non-hybrid architecture) are compared with three Pareto-optimal solutions whose characteristics are given in Table 3. It can bee seen that several optimized solutions clearly dominate the initial configuration of the locomotive, designed with a traditional sequential approach.

The flat shape of the Pareto-front and the small number Pareto-optimal configurations found can be explained by the dominance of the annual fuel cost in relation to the global system cost. It can be 
Table 3

Design variables and main objectives of three Pareto-optimal configurations compared with the initial hybrid locomotive (LHyDIE)

\begin{tabular}{lrrrr}
\hline Design variables and objectives & LHyDIE & P1 & P2 & P3 \\
\hline Number of battery cells in series & 300 & 249 & 230 & 143 \\
Number of battery blocks in parallel & 4 & 8 & 9 & 10 \\
Number of ultracapacitor cells in series & 200 & 175 & 20 & 20 \\
Number of ultracapacitor blocks in parallel & 8 & 1 & 1 & 1 \\
Diesel engine nominal power [kW] & 215 & 174 & 162 & 151 \\
DC bus voltage [V] & 540 & 645 & 631 & 625 \\
Converter switching frequency [kHz] & 2 & 7 & 8 & 10 \\
Climatic cost (tCO2/year) & 301 & 288 & 287 & 286 \\
System cost [k€/year] & 183 & 172 & 178 & 189 \\
Fuel cost (k€/year) & 153 & 146 & 145 & 145 \\
Diesel engine cost (k€/year) & 22.4 & 19 & 18 & 17 \\
Battery and ultracapacitor cost (k€/year) & 7.6 & 7 & 18 & 27 \\
\hline
\end{tabular}

seen from Table 3 that it represents about $80 \%$ of the global cost for all hybrid architecture. Since both objectives are mainly correlated with fuel consumption there is no clear trade-offs which leads to a "weak" Pareto-front. It is interesting to note for this application that climatic and environmental concerns coincide with economic interests... The climatic cost minimization is achieved for the "just enough sized" solution (i.e. P3) which presents the lower diesel engine nominal power and a small number of ultracapacitor and battery cells. However, the system cost is not optimal in this case because batteries and ultracapacitors are subject to a higher number of cycles during the driving mission. This explains the increase of the cost related to ultracapacitors and batteries, which is penalized trough the lifetime estimators.

\section{Conclusions}

In this work, an original integrated design approach based on multiobjective optimization with genetic algorithms has been developed for the design of a hybrid locomotive devoted to non-electrified areas. This approach aims at concurrently optimizing the system architecture, the element sizing and the energy management strategy instead of separating the global optimization problem into local sub-problems which can be sequentially solved. On the other hand, it considers multiple heterogeneous objectives (climatic and economic costs, lifetime) taking account of several constraints (volume, driving mission compliance). This approach has shown to be efficient by finding hybrid locomotive configurations that dominate those obtained with traditional methodologies based on problem simplification.

\section{References}

[1] J. Sobieszczanski-Sobieski, Multidisciplinary design optimization: an emerging, new engineering discipline, Advances in Structural Optimization, Kluwer, 1995, 483-496.

[2] N.M. Alexandrov and M.Y. Hussaini, Multidisciplinary Design Optimization - state of the art, in Proceedings of the ICASE/NASA Langley Workshop on Multidisciplinary Design Optimization, SIAM Proceedings Series, 1997.

[3] K. Sridhar, J.H. Lang and S.D. Umans, Integrated design of a boost converter, Proceedings of the Applied Power Electronics Conference and Exposition, APEC '95, Vol. 1, 1995, 160-168.

[4] M. Dilek and R.P. Broadwater, An introduction to integrated design in electrical distribution, IEEE Power Engineering Society Winter Meeting 2 (2002), 991-994. 
[5] B. Sareni, J. Regnier and X. Roboam, Integrated Optimal Design of Heterogeneous Electrical Energetic Systems using Multiobjective Genetic Algorithms, IREE (International Review of Electrical Engineering), ISSN 1827-6600, Vol. 1, N 1, 2006, 112-129.

[6] H. Tanaka, T. Sugie and T. Katayama, Simultaneous design of structure and control systems for two-degree-of-freedomcontroller, Proceedings of the 1999 IEEE International Conference on Control Applications 1 (1999), 131-136.

[7] C. Gezgin, B.S. Heck and R.M. Bass, Simultaneous design of power stage and controller for switching power supplies, IEEE Transactions on Power Electronics 12(3) (1997), 558-566.

[8] M. Thiounn, PLATHEE - A Platform for Energy Efficiency and Environmentally Friendly Hybrid Trains, 8th World Congress on Railway Research, COEX, Seoul, Korea, May 18-22, 2008.

[9] C.R. Akli, Conception systémique d'une locomotive hybride autonome, PHD thesis, INP Toulouse, June 2008.

[10] C.R. Akli, X. Roboam, B. Sareni and A. Jeunesse, Energy Management and Sizing of a hybrid locomotive, European Conference on Power Electronics (EPE'07), 2007, 1-10.

[11] L.A. Graham, Greenhouse Gas Emissions from Light Duty Vehicles Under a Variety of Driving Conditions, IEEE EIC Climate Change Technology (2006), 1-8.

[12] S. Drouilhet and B.L. Johnson A battery life prediction method for the hybrid power applications, 35th AIAA Aerospace Sciences Meeting and Exhibit, 1997.

[13] K. Deb, S. Agrawal, A. Pratab and T. Meyarivan, A fast-elitist non-dominated sorting genetic algorithm for multiobjective optimization: NSGA-II, Proceeding of the Parallel Problem Solving from Nature VI Conference, Athens, Greece, 2000, $849-858$ 